\title{
Salarios de eficiencia en un contexto de agentes heterogéneos y racionalidad limitada ${ }^{1}$
}

\author{
Efficiency Wages in a Context of \\ Heterogeneous Agents and Bounded \\ Rationality
}

\section{Salários de eficiência num contexto de agentes heterogêneos e racionalidades limitada}

1 Este artículo se deriva de la tesis de doctorado en curso en Economía del Desarrollo sobre la relación entre salarios y productividad en Colombia, financiada por FLACSO-Ecuador.

2 Ingeniero civil. Magíster en Economía y Magíster en Economía del Medio ambiente y de los recursos naturales. 


\title{
Resumen
}

Este artículo simula un mercado artificial del trabajo mediante algoritmos genéticos, con el propósito de determinar en un contexto de salarios de eficiencia y racionalidad limitada, los efectos de la heterogeneidad de firmas y trabajadores, sobre la dinámica de los salarios y el empleo. Se concluye que la heterogeneidad en la calificación de los trabajadores, o en su percepción del salario de referencia, obliga a las firmas a competir ofreciendo salarios más altos, especialmente cuando la economía está sujeta al régimen de salario mínimo. En el mercado de trabajadores menos calificados, en ausencia de salario mínimo no existe equilibrio estable, porque el aprendizaje inductivo puede conducir a las firmas a optar por dos estrategias de salario diferentes.

Palabras clave: salarios de eficiencia; racionalidad limitada; algoritmos genéticos.

Clasificación JEL: J41, Do1, D82.

\begin{abstract}
This paper simulates an artificial labor market using genetic algorithms, with the purpose of determining in a context of efficiency wages and bounded rationality, the effects of heterogeneity of firms and workers about the dynamics of wages and employment. It is concluded that the heterogeneity in the qualification of workers, or their perception of the reference wage, forces firms to compete offering higher salaries, especially when the economy is subject to the minimum wage regime. In the market for less skilled workers, in absence of minimum wage there is no stable equilibrium, because the inductive learning can lead firms to choose between two different strategies salary.
\end{abstract}

Keywords: efficiency wages; bounded rationality; genetic algorithms.

\section{Resumo}

Este artigo simula um mercado artificial do trabalho através de algoritmos genéticos, a fim de determinar, num contexto de salários de eficiência e racionalidade limitada, os efeitos da heterogeneidade de empresas e trabalhadores sobre a dinâmica dos salários e do emprego. Conclui-se que a heterogeneidade na qualificação dos trabalhadores ou na sua percepção do salário de referência, força às empresas a competir oferecendo salários mais elevados, especialmente quando a economia está atrelada ao regime de salário mínimo. No mercado de trabalhadores menos qualificados, e na ausência de salário mínimo, no existe equilíbrio estável porque a aprendizagem indutiva pode levar às empresas a optar por duas estratégias de salário diferentes.

Palavras-chave: salários de eficiência; racionalidade limitada; algoritmos genéticos.

cC) (i) Este trabajo está bajo la licencia Creative Commons Attribution 3.0

¿Cómo citar este artículo? / How to quote this article?

Méndez, Jhon. «Salarios de eficiencia en un contexto de agentes heterogéneos y racionalidad limitada». Sociedad y economía, n² 29 (julio - diciembre 2015): 203-232. 


\section{Introducción}

Los modelos de salarios de eficiencia postulan que por explicaciones no walrasianas -como la información asimétrica, la selección adversa y la rotación laboral- o bajo premisas psicológicas y sociológicas -como la moral, la justicia y los grupos de presión internos-, los empleadores tienen buenos motivos para pagar a sus trabajadores salarios superiores a aquel que equilibraría el mercado. Esto genera racionamiento de los puestos de trabajo y desempleo involuntario.

La información asimétrica ocurre porque las firmas no pueden monitorear el esfuerzo de sus trabajadores. A partir de esta premisa, Solow (1979) desarrolla un modelo en el que propone la relación directa entre el salario de los trabajadores y su esfuerzo; de donde deduce que las empresas están dispuestas a pagar un salario más alto (salario de eficiencia), para incentivar un mayor nivel de productividad en su personal.

El modelo de selección adversa asume que los trabajadores son heterogéneos en cuanto a su dotación de habilidades, y existe correlación positiva entre el salario de reserva y las habilidades que determinan la productividad del trabajador. Esto condiciona que las firmas paguen salarios altos, con el propósito de atraer a los trabajadores más hábiles y elevar el valor esperado de la productividad (Yellen 1984).

El modelo de Solow (1979) y el de selección adversa presentan similitudes y diferencias importantes. En ambos casos, la información asimétrica no permite que las firmas paguen salarios diferenciados en función de la productividad de sus trabajadores. Por otra parte, mientras en el modelo de Solow el salario alto incentiva la productividad del trabajador a través de su mayor esfuerzo, en el modelo de selección adversa se omite dicha relación; y son la heterogeneidad de los trabajadores, y la conjetura de relación directa entre la habilidad y el salario de reserva los supuestos claves para la existencia del salario de eficiencia.

Sin embargo, a un nivel agregado, el supuesto de que el salario de reserva incrementa en función de las habilidades de los individuos resulta controversial. Por ejemplo, Bosworth, Dawkins y Stromback (1996) se preguntan ¿de dónde provienen los individuos con mayores habilidades, cuando aumenta exógenamente el salario de mercado? Los mismos autores plantean, citando las investigaciones de Weiss (1980) y Weiss y Wang (1990), que pueden provenir del sector informal, es decir, los trabajadores auto empleados. Sin embargo, en promedio, los trabajadores informales obtienen ingresos por debajo del salario del mercado, así que, en promedio, sus habilidades estarían por debajo de las habilidades de los trabajadores del sector formal.

La evidencia empírica tampoco es concluyente. Utilizando datos de los trabajadores en Alemania, Prasad (2003) encontró correlación negativa entre la razón salario de reserva-oferta de salario y el nivel de habilidades de los individuos. Durán (2005) determinó que las características personales que indican productividad, como son la edad, el nivel educativo y la experiencia, inciden de manera importante en la determinación del salario de reserva. Monte, Ramalho y Pereira (2011) encontraron evidencia a favor de una relación positiva entre el salario de reserva y el nivel de escolaridad de los trabajadores. 
Este artículo simula un mercado artificial del trabajo mediante algoritmos genéticos, con el propósito de determinar la dinámica de los salarios y el empleo, cuando se incorporan heterogeneidades en firmas y trabajadores al modelo de salarios de eficiencia de Solow (1979). Es decir, se asume la existencia de una relación positiva entre los salarios y el esfuerzo; pero no induce la heterogeneidad de los trabajadores mediante la desigualdad en los salarios de reserva, porque no se hace uso de la relación directa entre la habilidad y el salario de reserva.

La heterogeneidad de los trabajadores se incorpora en la simulación, asumiendo diferencias en la percepción de los individuos sobre su salario de referencia y mediante la pluralidad de habilidades. La regla de emparejamiento consiste en que las firmas que pagan mejores salarios contratan los trabajadores más productivos.

La simulación a través de algoritmos genéticos recoge las críticas de la economía conductual ${ }^{3}$ sobre los supuestos de racionalidad perfecta y el agente representativo de la economía ortodoxa. La economía conductual argumenta que los agentes son heterogéneos y están dotados de racionalidad limitada ${ }^{4}$ : no tienen información perfecta, tienen limitaciones cognitivas, son incapaces de procesar gran cantidad de información $\mathrm{y}$, por tanto, no toman sus decisiones siguiendo un razonamiento deductivo y con una estrategia de optimización. En esas condiciones, el algoritmo genético (AG) es una herramienta de simulación útil, porque permite reproducir estrategias de aprendizaje inductivas, propias de agentes con racionalidad limitada (Kosciuczyk 2012). Ciertamente, los agentes artificiales del algoritmo genético siguen un razonamiento inductivo, porque aprenden de su entorno copiando las estrategias más exitosas.

La crítica aplica para el modelo de Solow (1979) porque, aunque se considera la información asimétrica (al reconocer que la firma desconoce el esfuerzo de los trabajadores), para resolver el proceso de optimización, las firmas deben conocer su función de producción y la función de esfuerzo de los trabajadores, lo cual no es realista. En el caso especial de este artículo, la simulación mediante algoritmos genéticos permite descubrir cambios de régimen en el salario e identificar sus causas, así como determinar el efecto de la política de salario mínimo en el contexto simulado.

Este artículo está organizado de la siguiente forma: la primera parte revisa la teoría de salarios de eficiencia, sustentándola en la correlación directa entre los salarios y el esfuerzo, y el modelo de selección adversa que incorpora la heterogeneidad de los agentes; en la segunda parte se presenta una introducción a los algoritmos genéticos y sus aplicaciones en la economía; en la tercera, se explica el modelo base para las simulaciones; en la cuarta, se exponen y comentan los resultados de las simulaciones; y finalmente se presentan las conclusiones.

3 La economía conductual se define como la combinación de la psicología y la economía que investiga lo que sucede en los mercados cuando los agentes se distancian del individuo racional definido en los modelos económicos ortodoxos.

4 Simon (1955) define la racionalidad limitada como el término que describe el proceso de decisión de un individuo, considerando limitaciones cognoscitivas tanto de conocimiento, como de capacidad computacional. La idea es que el ser humano, ante estas limitaciones que le son propias, busca, antes que maximizar, niveles de conformidad o satisfacción. 


\section{Salarios de eficiencia}

La teoría de salarios de eficiencia afirma que la productividad de los trabajadores en la empresa está correlacionada positivamente con el salario. Si los trabajadores reciben un salario relativamente más alto, pueden ser más leales, laboriosos y trabajarán más duro para mantener su puesto de trabajo. Las empresas fijan los salarios de forma unilateral y deciden no reducir los salarios hasta el nivel de equilibrio del mercado debido al efecto perjudicial que esto tendría sobre el esfuerzo del trabajador, su productividad y, en última instancia, sobre los beneficios de la empresa. Los salarios de eficiencia son un concepto adoptado por el nuevo keynesianismo, para explicar el desempleo involuntario a partir de la formación de salarios, por encima del salario que vacía el mercado. Además, ya que con el salario de eficiencia hay mayor probabilidad de que el pago cubra el salario de reserva, aumenta el número de personas en búsqueda de trabajo.

Solow (1979) es pionero en la conceptualización y formalización de la teoría de los salarios de eficiencia. Su modelo supone una relación directa entre el salario que recibe el trabajador y su productividad, lo que incide en lo que Solow llamó trabajo efectivo. Solow concluye que el salario real óptimo a pagar por la firma depende de la especificación de la relación entre salario y esfuerzo, y no de la relación entre la oferta y demanda del mercado de trabajo que asume la teoría neoclásica.

Para obtener esa conclusión, Solow (1979) define una función de producción, en la que el volumen de producción $q$ de la empresa depende tanto del número de trabajadores contratados $L$, como del esfuerzo de estos $n$.

$$
q=q(n L) \quad q^{\prime}(.)>0, q^{\prime \prime}(.)<0
$$

Después introduce la hipótesis de que el esfuerzo es una variable que depende positivamente del salario $w$ que paga la empresa:

$$
n=n(w) \quad n^{\prime}(w)>0
$$

La empresa representativa se enfrenta al problema de maximización de beneficios, para lo cual debe decidir cuánto trabajo contratar y cuánto salario pagar a sus trabajadores:

$$
\max _{L, W} \pi=p * q(n(w) l)-w l
$$

La solución del problema de maximización (3), corresponde al punto en que la elasticidad del esfuerzo respecto al salario es igual a uno. Esto es lo que se conoce como la condición de Solow:

$$
e^{\prime}(w) * \frac{w}{e}=1
$$


Luego de que la empresa encuentre el salario $w^{*}$ que maximiza su beneficio, fijará su demanda de trabajo $l^{*}$, donde la productividad marginal del trabajo sea igual al salario de eficiencia. Si en la economía existen $N$ empresas idénticas que operan en mercados competitivos y todas pagan salarios de eficiencia, y si ese salario óptimo está por encima del salario que vacía el mercado, se generará desempleo involuntario (Caraballo 1996).

$$
\text { Empleo total }=N * l^{*}
$$$$
\text { si } N * l^{*}<\bar{L} \rightarrow U(\% \text { Desem })=\frac{\bar{L}-N * l^{*}}{\bar{L}} * 100
$$

(5)

En los modelos de selección adversa, la productividad $\theta$ del trabajador depende de su habilidad. Los trabajadores son heterogéneos en cuanto a su dotación de habilidades, así que $\theta_{i} \in[\underline{\theta}, \bar{\theta}]$, y los empresarios conocen la distribución de habilidades de la población. Se supone también que el salario de reserva $r(\theta)$ del trabajador y su habilidad están positivamente correlacionados: $\frac{\mathrm{dr}}{\mathrm{d} \theta}>0$. Por ende, la disposición a trabajar por un salario bajo es considerada una señal de menor nivel de habilidades poseídas por los trabajadores baratos (Riveros 1993).

Bajo información asimétrica, la empresa no puede distinguir a los trabajadores, así que ofrece un salarió único $w$. Si existen muchas empresas, la demanda de la firma $z(w) \in(0, \infty)$ cuando el valor esperado de la productividad iguale al salario: $E\left\{\theta \mid \theta: \mathrm{r}(\theta) \leq w^{*}\right\}=w^{*}$. El salario de equilibrio $w^{*}$ resultante funciona como un mecanismo de autoselección que atrae a los trabajadores con más habilidades, porque si se reduce el salario, también cae el valor esperado de la productividad. El resultado es que en promedio, las firmas pagarían un salario de contratación superior al salario de mercado.

Ya se comentó que una de las razones para incorporar la heterogeneidad de los trabajadores, a partir de la estructura del modelo de Solow (1979), son las críticas al supuesto de correlación positiva entre la habilidad y el salario de reserva. Otro punto a favor de la modelación de Solow es que va a permitir que las estrategias de los agentes en la simulación tengan en cuenta las condiciones del mercado. Siguiendo a Summers (1988), el esfuerzo del trabajador puede hacerse depender, además del salario percibido, de la tasa de desempleo y el salario promedio del mercado. Con esto, la condición (4) queda de la siguiente forma:

$$
e^{\prime}\left(w, w_{a}, u\right) * \frac{w}{e}=1
$$

Mientras que en el modelo de selección adversa, pagar salarios bajos implica necesariamente baja productividad promedio; cuando el esfuerzo depende no solo del salario sino del salario de referencia y la tasa de desempleo, la estrategia de salario bajo es otra estrategia viable para las firmas, porque $\frac{d e}{d w_{a}}<0$. Con salarios pequeños cae el producto marginal del trabajo, así que se pueden contratar 
más trabajadores y cae la tasa de desempleo, lo que también trae un efecto positivo sobre el esfuerzo, ya que $\frac{d e}{d u}<0$.

\section{Algoritmos genéticos}

Los algoritmos genéticos son procedimientos estocásticos adaptativos que sirven para resolver problemas de búsqueda de la solución óptima a un problema de optimización. Están inspirados en la biología y, concretamente, en la teoría de la evolución de las especies de Darwin. Imitando este proceso, los algoritmos genéticos logran ir creando soluciones a problemas de distinta naturaleza en múltiples disciplinas.

En función de su uso en la economía, los algoritmos genéticos pueden ser clasificados como una herramienta instrumental (optimización) o como herramienta descriptiva (modelar el comportamiento de los sistemas).

Cuando en un modelo el comportamiento de los agentes y sus interacciones se torna muy complejo, se vuelve matemáticamente intratable y las técnicas de optimización tradicionales no pueden utilizarse para determinar la solución óptima. El algoritmo genético se usa frecuentemente como procedimiento de optimización, gracias a su capacidad para encontrar buenas soluciones, aun en ambientes confusos e inestables. Como ejemplo puede mencionarse a Winoto (2002), quien emplea un algoritmo genético para determinar los castigos óptimos (penas en años de cárcel y multas) para diferentes tipos de crímenes.

Sin embargo, el uso más atrayente de los algoritmos genéticos es como herramienta descriptiva, es decir, en la modelación del comportamiento de los agentes económicos. Comúnmente la intención al utilizar los algoritmos genéticos en la modelación económica es mejorar la comprensión del fenómeno observado, mediante la recreación de escenarios y la observación del comportamiento de las variables de interés. En contraste con la modelación de la economía neoclásica, la modelación a través de algoritmos genéticos no asume que las acciones de los individuos sean completamente racionales, es decir, funciona en un contexto de racionalidad limitada.

La economía del comportamiento sostiene que los agentes económicos son heterogéneos, y se caracterizan por diversas competencias, creencias y expectativas, así como por diferentes grados de acceso y capacidad de procesamiento de los flujos de información. También reaccionan de manera local y autónoma en un ambiente dado. Los agentes económicos no son globalmente inteligentes, y el aprendizaje para la toma de decisiones tiende a ser más descentralizado que centralizada y más inductivo que deductivo.

Esto crea un nuevo marco conceptual en el que los propios agentes son sujetos evolutivos, no dotados a priori de ningún concepto de racionalidad, sino que construyen sus comportamientos en el curso del aprendizaje, por tanto deben tener la capacidad de repetir, imitar e innovar estrategias. Este contexto hace de los algoritmos genéticos una buena opción como herramienta para la modelación económica.

Como lo explica Riechmann: "Una de las metáforas que puede usarse para representar el aprendizaje en economía es la forma de aprendizaje de los algoritmos genéticos. El aprendizaje en los algoritmos genéticos es una forma de 
aprendizaje social más que individual. El aprendizaje social significa aprender unos de los otros" $(1998,225)$.

Geisendorf (1999) y Schunk (2003) son aplicaciones con estas características, porque además de modelar el comportamiento de los recursos naturales renovables y no renovables respectivamente, utilizan el modelo para evaluar el comportamiento de las variables como capturas o extracción de los recursos, ante algunas medidas con propósitos de conservación y uso eficiente de los recursos.

Méndez (2008) simula el impacto de la aplicación de las tasas retributivas en Colombia, considerando el comportamiento estratégico de las empresas contaminadoras, originado por su racionalidad limitada y el cumplimiento parcial de la autoridad ambiental, en sus actividades de facturación y monitoreo.

Faria (2004) modela un mercado laboral artificial mediante algoritmos genéticos, en el cual se intenta mostrar en qué circunstancias surge la cooperación entre los agentes: firmas y trabajadores, y cómo emerge endógenamente el equilibrio a partir de las interacciones descentralizadas de agentes autónomos y adaptativos.

Los dos tipos de agentes, empresas y trabajadores, tienen diferentes funciones de pago y habilidades de aprendizaje que les permiten desarrollar unas normas de comportamiento que son activadas selectivamente. En un marco de contratos incompletos, cada salario ofrecido por la empresa se asocia a un nivel de esfuerzo elegido por el empleado. De acuerdo con las rentabilidades obtenidas, las reglas de comportamiento son redefinidas y se obtienen nuevos pagos en la próxima iteración. Este proceso se repite un gran número de veces. Posteriormente se introdujeron cambios al modelo, incluyendo la reciprocidad, diversidad y tasa de desempleo con el propósito de encontrar nuevos resultados. Lo que evidencia este artículo es cómo las simulaciones computacionales basadas en agentes pueden ayudar a explicar las complejas relaciones entre macro y micro realidades emergentes y, en consecuencia, dar otro punto de vista acerca de las estructuras de interacción, heterogeneidad y procesos evolutivos de agentes adaptativos.

\subsection{Estructura y funcionamiento}

El algoritmo genético artificial atribuido a Holland (1975) consiste en un número de cadenas (cromosomas) que codifican la información sobre el comportamiento de diferentes individuos, de una población en su ambiente, y algunos operadores del algoritmo genético modifican estas cadenas. Los comportamientos son evaluados mediante una función de ajuste, que simula el ambiente en el que se desenvuelven los individuos. Las cadenas mejor adaptadas obtienen las puntuaciones más altas, lo que les asegura mayor probabilidad de ser escogidos por el operador de selección, para intervenir en la etapa de reproducción. Dichas cadenas experimentan los procedimientos de cruce y mutación, lo que produce nuevos individuos (cadenas) descendientes de los anteriores, los cuales comparten ciertas características de sus padres. De esta manera, se produce una nueva población que reemplaza a la anterior y experimenta las mismas operaciones, hasta que la población converge.

En definitiva, la implementación de un algoritmo genético estándar consta de cinco pasos: codificación, selección, reproducción, cruce y mutación. Los últimos cuatro pasos son procesos estocásticos que pueden dividirse en procesos generadores y procesos restrictivos. 
Los procesos generadores desarrollan nuevas estrategias o formas de comportamiento de los individuos; forman parte de estos la reproducción y los operadores genéticos de cruce y mutación.

Los procesos restrictivos reducen el número de estrategias disponibles para los individuos mediante el operador de selección. Se trata de depurar las estrategias permitiendo que continúen solo las más competitivas.

\subsubsection{Codificación}

En el AG estándar los individuos (sus estrategias) se representan mediante una cadena de bits 5 (cadena de ceros y unos). Entonces un individuo genético de longitud $L$ consiste de $L$ símbolos o y 1 . El conjunto completo de los posibles individuos genéticos distintos de longitud $L$ será: $S \in\{0,1\}^{L}$ y su cantidad: $|S| \equiv N=2^{L}$

Estos individuos genéticos se transmiten de generación en generación durante varias épocas. Al conjunto de individuos de una misma generación se le denomina población. La población en un algoritmo genético consta de un subconjunto de dimensión $M$ de todos los posibles individuos genéticos distintos de longitud $L$; es decir $M<N$. La cantidad de todas las posibles poblaciones genéticas " $\Im$ " está dada por:

$$
J=\left(\begin{array}{c}
M+N-1 \\
M
\end{array}\right)
$$

La inicialización de la población normalmente se hace de manera aleatoria.

\subsubsection{Selección}

Para seleccionar los individuos genéticos que pasan de una generación a otra, se debe obtener el valor que le corresponde a cada individuo de la población, decodificando la cadena de bits, y después se evalúa su competitividad respecto a los otros (en el problema a ser resuelto), utilizando alguna función de ajuste. Si el algoritmo genético funciona bien y el problema está correctamente planteado, el promedio de la función de ajuste, a medida que transcurren las distintas generaciones, debe declinar.

Dentro del contexto de aprendizaje social caracterizado por el algoritmo genético, la asignación del ajuste de cada individuo genético es una parte crucial en el proceso de aprendizaje, porque permite decidir cuáles individuos (estrategias) se reproducen y cuáles no.

\subsubsection{Reproducción}

La reproducción es el proceso mediante el cual se deriva una nueva población, a partir de los individuos de la generación precedente, con mejor medida de ajuste.

5 Realizando un paralelo con la biología, la cadena de bits simula a los cromosomas (cadenas de genes). Un gen es información que codifica las características de un individuo. 
La reproducción puede ser interpretada como aprendizaje por imitación, ya que los individuos (agentes económicos) con peor estrategia copian las estrategias más exitosas de los miembros de la población.

\subsubsection{Cruce}

El operador de cruce toma dos padres y divide sus cadenas en dos partes, con punto de cruce seleccionado al azar. A continuación se crean individuos genéticos nuevos, por la recombinación de las partes de sus dos padres, de forma tal que los descendientes heredan genes de cada uno de ellos. Este operador se conoce como operador de cruce basado en un punto (figura 1). Habitualmente el operador de cruce no se aplica a todos los pares de individuos que han sido seleccionados para emparejarse, sino de manera aleatoria con una probabilidad que está entre $[0,5 ; 1,0]$.

Figura 1. Cruce basado en un punto

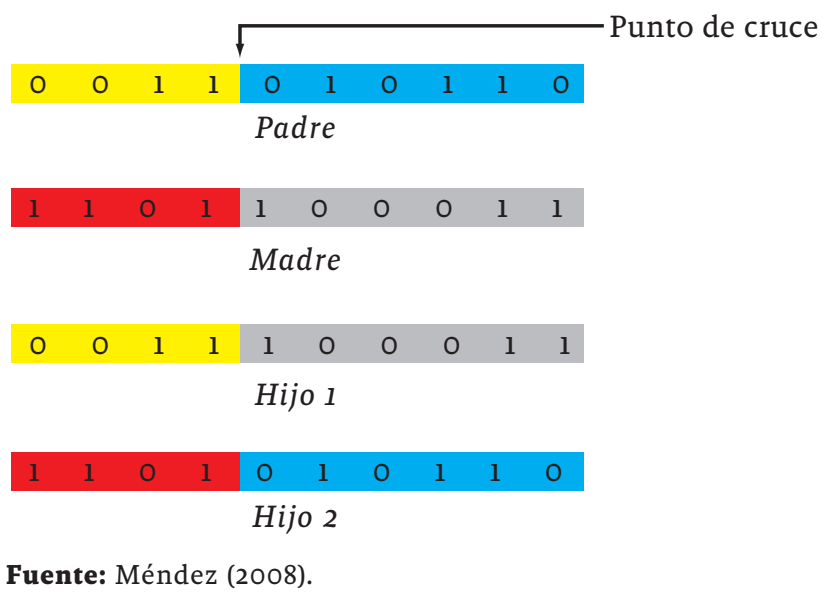

La operación de cruce puede ser interpretada como aprendizaje por comunicación, porque los individuos representados por las cadenas de bits toman cada uno parte de las estrategias del otro, con la intención de crear nuevas y mejores estrategias.

\subsubsection{Mutación}

La mutación se aplica a cada descendiente de manera individual, y consiste en la alteración aleatoria y con probabilidad pequeña de algún bit de la cadena. La posición de la cadena cuyo bit tendrá la posibilidad de mutar también es seleccionada al azar (figura 2).

La mutación puede ser vista como aprendizaje por experimentación, y asegura que ninguna estrategia del conjunto disponible $S$ tenga probabilidad cero de ser explorada. 
Figura 2. Operador de mutación

\begin{tabular}{ccccccccccc}
0 & 0 & 1 & 1 & 1 & 0 & 0 & 0 & 1 & 1 \\
& \multicolumn{1}{c}{ Hijo } & 1 \\
0 & 0 & 1 & 1 & 0 & 0 & 0 & 0 & 1 & 1
\end{tabular}

Fuente: Méndez (2008).

\section{Modelo del mercado del trabajo}

El modelo se apoya en la conceptualización y formalización de la teoría de los salarios de eficiencia de Solow (1979), para definir las características de los agentes del mercado artificial del trabajo, que será simulado mediante los algoritmos genéticos. Se asumen agentes que ofrecen con su trabajo un esfuerzo decreciente positivo en función del salario real, conforme a la hipótesis de salarios de eficiencia, y firmas que pagan salarios superiores al que equilibra el mercado, para generar un esfuerzo en sus trabajadores que maximice sus beneficios.

Las firmas tienen una función de producción que está dada por:

$y=A *(e * l)^{a}$

Donde $y$ es el producto, $A$ es un parámetro tecnológico, $e$ es el nivel de esfuerzo desarrollado por los trabajadores, $l$ es el trabajo contratado por la firma y $\alpha$ la elasticidad del trabajo.

Su objetivo es la maximización de sus beneficios, y para ello deben decidir el salario $w$ a pagar y el número de trabajadores $l$ por contratar.

$$
\max _{w, l} \pi=p * A *(e * l)^{a}-w l
$$

Siguiendo a Summers (1988), se asume que el esfuerzo del trabajador depende del salario percibido, la tasa de desempleo y el salario promedio del mercado:

$$
\begin{aligned}
& e=\left\{\begin{array}{cc}
\left(\frac{w-x}{x}\right)^{\beta} & w>x \\
0 & w \leq x
\end{array}\right\} \\
& x=(1-b * u) w_{a}
\end{aligned}
$$

Donde $0<\beta<1, x$ es una medida de las condiciones del mercado, $b>0$, el parámetro $u$ es la tasa de desempleo y $w_{a}$ es el salario alternativo o de referencia. Si $b=1$ entonces $x$ es el salario alternativo multiplicado por la proporción de trabajadores que están empleados. La principal característica de esta función 
definida por las ecuaciones (10) y (11) es que el esfuerzo incrementa menos proporcionalmente que $w-x$ para $w>x$.

Dadas las funciones de producción (8) y de esfuerzo (10), (11), y recordando que en la solución óptima (9), bajo homogeneidad de trabajadores y firmas, la elasticidad del esfuerzo respecto al salario es igual a uno.

$$
\beta * \frac{w}{\left(\frac{w-x}{x}\right)^{\beta}} *\left(\frac{w-x}{x}\right)^{\beta-1} * \frac{1}{x}=1
$$

De donde se deriva la expresión para el salario óptimo en función del salario alternativo y la tasa de desempleo:

$$
w^{*}=\frac{1-b u}{1-\beta} w_{a}
$$

En equilibrio, todas las firmas pagan el mismo salario, así que $w=w_{a}$. Reemplazando esto en (13), se obtiene la tasa de desempleo de equilibrio.

$$
u^{*}=\frac{\beta}{b}
$$

A partir de (10) y (ll) y con $w=w_{a}$ se encuentra el nivel de esfuerzo óptimo:

$$
e^{*}=\left[\frac{w_{a}-(1-b * u) w_{a}}{(1-b * u) w_{a}}\right]^{\beta}=\left(\frac{\beta}{1-\beta}\right)^{\beta}
$$

Una de las condiciones de primer orden del proceso de maximización de beneficios (9) es:

$$
w=e F^{\prime}(e l)
$$

El empleo total $L^{*}$ en el equilibrio es:

$$
L^{*}=\left(1-u^{*}\right) * \bar{L}
$$

Donde $\bar{L}$ es la fuerza de trabajo. Si en el mercado existen $N$ firmas homogéneas, cada empresa contrata $l^{*}=L / N$ trabajadores.

A partir de (15), (16) y (17) se puede obtener el salario de equilibrio:

$$
w^{*}=\left(\frac{\beta}{1-\beta}\right)^{\beta} F^{\prime}\left[\left(\frac{\beta}{1-\beta}\right)^{\beta} * \frac{1-\frac{\beta}{\mathrm{b}} * \bar{L}}{N}\right]
$$


Las expresiones $w^{*} y l^{*}$ arrojan valores del salario y el empleo que maximizan los beneficios de la firma, bajo el supuesto tradicional de la economía ortodoxa de homogeneidad de firmas y trabajadores. La tabla 1 muestra los valores asumidos para los parámetros ${ }^{6}$ de las funciones de producción y esfuerzo, así como la tasa de desempleo resultante, el valor del salario óptimo, la demanda de trabajo de la firma y el esfuerzo desarrollado por los trabajadores.

Tabla 1. Valores de los parámetros

\begin{tabular}{|c|c|c|}
\hline \multicolumn{3}{|c|}{ Parámetros para la simulación } \\
\hline \multirow{2}{*}{$\begin{array}{l}\text { Función de } \\
\text { producción: }\end{array}$} & $\boldsymbol{A}$ & $a$ \\
\hline & 179 & 0,62 \\
\hline \multirow[t]{2}{*}{ Función de esfuerzo: } & $\beta$ & b \\
\hline & 0,1875 & 2,0 \\
\hline \multicolumn{2}{|c|}{ Fuerza de trabajo $(\bar{L})$} & 2.560 \\
\hline \multicolumn{2}{|l|}{ Número de firmas $(N)$} & 40 \\
\hline \multicolumn{3}{|c|}{ Resultados } \\
\hline \multicolumn{2}{|c|}{ Tasa de desempleo $\left(u^{*}\right)$ : } & 0,0937 \\
\hline \multicolumn{2}{|l|}{ Empleo $\left(l^{*}\right)$ : } & 58 \\
\hline \multicolumn{2}{|l|}{ Esfuerzo $\left(e^{*}\right)$ : } & 0,7596 \\
\hline \multicolumn{2}{|l|}{ Salario $\left(w^{*}\right)$ : } & 20 \\
\hline
\end{tabular}

Fuente: elaboración propia.

\section{Simulación}

La simulación del mercado artificial del trabajo tiene como propósito descubrir la dinámica de los salarios y el empleo cuando se incorporan heterogeneidades en trabajadores y firmas. Esta estrategia de simulación mediante algoritmos genéticos relaja los supuestos usuales de la economía ortodoxa del agente racional tradicional y el concepto de agregación del agente representativo, permitiendo que sean las interrelaciones entre los agentes y el aprendizaje inductivo quienes rijan la dinámica del mercado.

No obstante, en la realidad las firmas no conocen la especificación de la relación entre salario y esfuerzo de sus trabajadores $e(w)$, así que no resuelven la ecuación (4). Tampoco conocen o estiman la función de producción (1) para hallar el producto marginal del trabajo y determinar la demanda óptima de trabajo $l^{*}$. Consecuentemente, es imposible utilizar el razonamiento deductivo para resolver el problema (3), porque es impracticable. La estrategia de aprendizaje de los algoritmos genéticos permite a los agentes artificiales encontrar soluciones óptimas al problema (3), sin los requerimientos del tratamiento matemático formal y sin necesidad de desarrollar cálculos y operaciones complejas.

Se simulan cuatro escenarios caracterizados por distintos supuestos sobre el comportamiento de los agentes del mercado (trabajadores y firmas). Básicamente

6 Los parámetros $A, \alpha, \beta$ y b fueron escogidos con el propósito de que los valores óptimos del salario $w^{*}$ y el empleo $l^{*}$ correspondieran a números enteros (para que el algoritmo genético pueda encontrar la respuesta exacta), que estuvieran dentro de los intervalos de estrategias definidas en el algoritmo genético para dichas variables, y se obtuviera una tasa de desempleo de equilibrio con un nivel similar a las observadas en la realidad. 
se contrasta la situación de homogeneidad de firmas y trabajadores, contra escenarios diferentes como homogeneidad de firmas - heterogeneidad de trabajadores, y heterogeneidad de firmas y trabajadores.

La heterogeneidad de firmas se integra al modelo mediante la diferenciación entre dos clases de empresas: firmas grandes que emplean tecnología y formas de organización sofisticadas y complejas, intensivas en capital y que demandan mano de obra calificada; y empresas pequeñas de organización simple, intensivas en mano de obra no calificada.

Dada dicha clasificación, se asume que el salario afecta la productividad de las firmas de dos formas diferentes. En el caso de las firmas que demandan mano de obra calificada, el salario afecta la elasticidad trabajo del producto, porque las empresas que pagan salarios más altos contratan a los trabajadores más productivos, ya que así atraen a los individuos más calificados, con mayor habilidad para desarrollar su trabajo.

$$
y=A * l^{a(w)}
$$

Por otra parte, las empresas intensivas en mano de obra no calificada pagan a sus trabajadores salarios de eficiencia para afectar su nivel de esfuerzo. La idea es que dada su menor productividad y bajos beneficios, este tipo de empresas pagan a sus trabajadores salarios más bajos que el promedio del mercado, así que el salario recibido no es suficiente motivación para que el trabajador desarrolle un $100 \%$ de su esfuerzo.

$$
y=A *[e(w) * l]^{a}
$$

Wadhwani y Wall (1991) presentan una discusión de las especificaciones (19) y (20), para representar el efecto de los salarios de eficiencia sobre el producto.

\subsection{Escenario de simulación 1}

En este escenario el mercado del trabajo está constituido por $N$ empresas idénticas y una fuerza de trabajo $\bar{L}$, todos los trabajadores con la misma función de esfuerzo y habilidades (homogeneidad de firmas y trabajadores). Los valores de los parámetros son los definidos en la tabla 1.

Las poblaciones iniciales de las estrategias de salario y empleo en el algoritmo genético son generadas a partir de distribuciones uniformes con límites iguales a los límites inferiores y superiores de los rangos de las variables salario $w \in[1,32]$ y empleo $l \in[1,64]$. La probabilidad de mutación es de 0,05. El salario alternativo $w_{a}$ se toma como el salario promedio del mercado.

$$
w_{a}=\frac{\sum_{j=1}^{N} w_{j}}{N}
$$


Las figuras 3 y 4 presentan los resultados de la simulación del mercado de trabajo mediante el algoritmo genético, para las variables salario y empleo. Se observa que aproximadamente en la generación sesenta se alcanza la estabilidad de las sendas del salario promedio que converge a $w^{*}=20$ y el empleo promedio que converge a aproximadamente $l^{*}=58$. La tasa de desempleo $u^{*}$ se estabiliza en un nivel ligeramente por debajo de $10 \%$ y el beneficio promedio de las firmas es $\pi^{*} \cong 750$ (sus figuras no se presentan aquí por problemas de espacio). Como se trata de los mismos resultados que los obtenidos mediante el análisis formal, se puede concluir de esta primera simulación que el algoritmo genético funciona correctamente. Se demuestra de esta forma que la estrategia de aprendizaje inductiva que rige la evolución de las estrategias en el algoritmo genético puede competir con el razonamiento deductivo del análisis formal.

Figura 3. Salario promedio del mercado

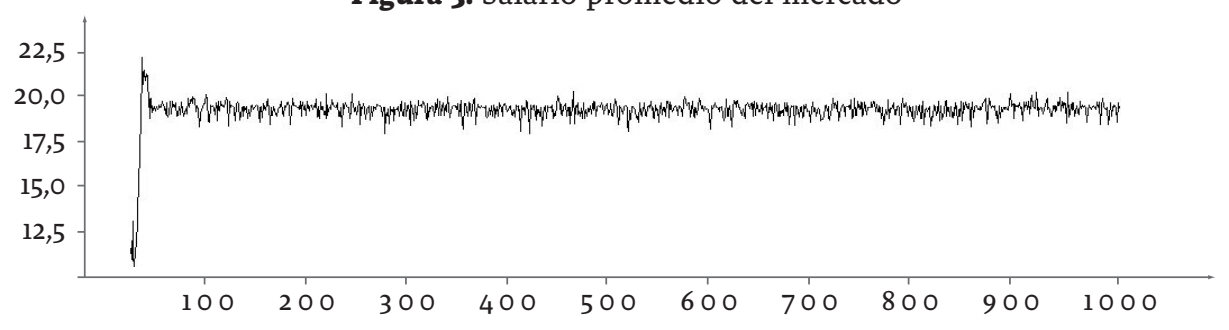

Fuente: elaboración propia.

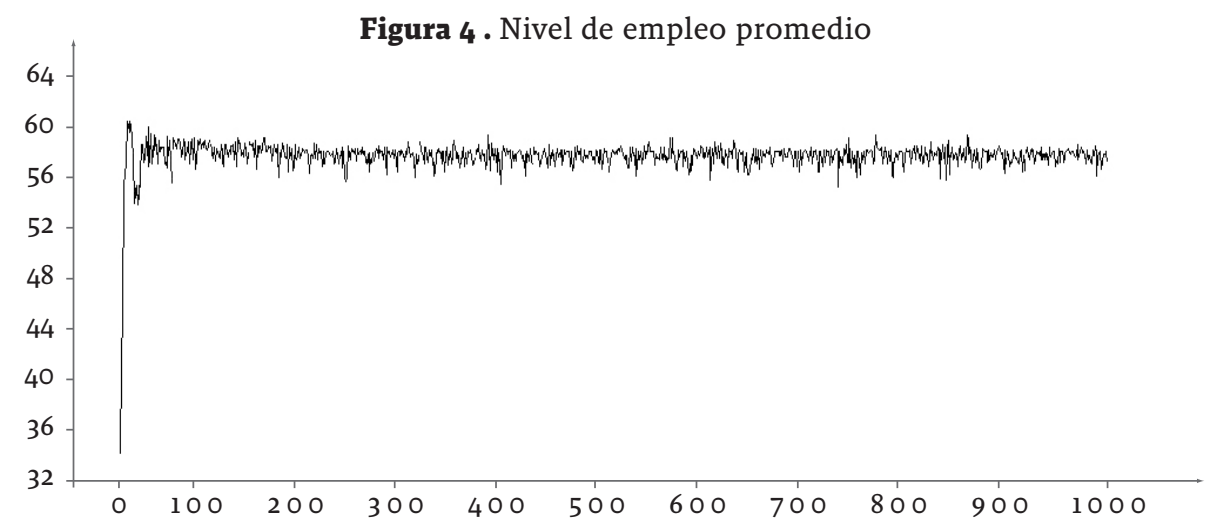

Fuente: elaboración propia.

\subsection{Escenario de simulación 2}

Este caso simula un mercado de trabajo para la mano de obra calificada, cuya demanda proviene, por ejemplo, de los sectores industriales más asociados a la tecnología y se pagan los salarios más altos. Los trabajadores son heterogéneos porque tienen diferentes niveles de calificación o habilidad para desarrollar su trabajo. Esta habilidad es representada por el parámetro de productividad $\beta_{i, \forall i{ }_{1, \ldots, L}}$ en la expresión (22). El criterio utilizado para el emparejamiento de 
firmas y trabajadores es que las empresas que ofrecen salarios más altos contratan a los trabajadores más calificados, es decir, con un parámetro $\beta_{i}$ más alto. Se asume que las firmas pagan a todos sus trabajadores contratados el mismo salario.

La función de producción de las firmas sigue la expresión (19) y adopta la siguiente forma:

$$
y_{i}=A * l_{i}^{a+\frac{\sum \beta_{j}}{l_{i}}}
$$

Por lo tanto, la elasticidad del trabajo es más alta, cuando se contratan los trabajadores más calificados, lo que depende de la oferta de salario de la firma. Los exponentes $\beta_{i}$ para los $L$ individuos que componen la fuerza de trabajo, son generados a partir de una distribución normal:

$$
\beta \sim N\left(0,1875 ; \sigma_{\beta}^{2}\right)
$$

Para que los trabajadores alcancen su máximo rendimiento, y se aproveche todo su conocimiento y habilidades, su esfuerzo debe ser de uno. Observando las expresiones (10) y (11), para que el esfuerzo $e^{*}=1$ se requiere que:

$$
\frac{w}{(1-b * u) w_{a}} \geq 2
$$

Si $\sigma_{\beta}{ }^{2}=0$, es decir que los trabajadores son homogéneos en cuanto a su nivel de calificación, y si la tasa de desempleo tiende a cero, para que $e^{*}=1$ se requiere que $w=2 w_{a}$. Lo cual puede ocurrir en la realidad porque se trata de mano de obra calificada que es contratada por el sector más productivo de la economía y que logra los mayores beneficios. Aquí se asume que $w_{a}=15$.

Las figuras 5, 6 y 7 muestran la dinámica de los salarios, cuando las varianzas del parámetro de calificación del trabajador son: $\sigma_{\beta}{ }^{2}=0,00, \sigma_{\beta}{ }^{2}=0,02$ y $\sigma_{\beta}{ }^{2}=0,05$. En la figura 5 se observa que cuando los trabajadores son homogéneos $\left(\sigma_{\beta}^{2}=0,0\right)$ el salario promedio es aproximadamente $w^{*}=30$, dos veces el salario promedio del mercado, así que las firmas pagan un salario lo suficientemente alto como para aprovechar completamente las habilidades de sus empleados $\left(e^{*}=1\right)$. Esto demuestra que el algoritmo genético funciona bien ya que puede replicar los resultados del análisis formal.

Las figuras 6 y 7 desvelan que tanto la oferta de salario de las firmas como su varianza, aumentan con la variabilidad en la habilidad de los trabajadores $\sigma_{\beta}{ }^{2}$. Para $\sigma_{\beta}{ }^{2}=0,02$ se tiene que el salario promedio es de aproximadamente $w^{*}=32$ (figura 4); cuando aumenta la variabilidad $\left(\sigma_{\beta}^{2}=0,05\right)$ el salario promedio $w^{*}$ fluctúa entre 40 y 60 (figura 7). 


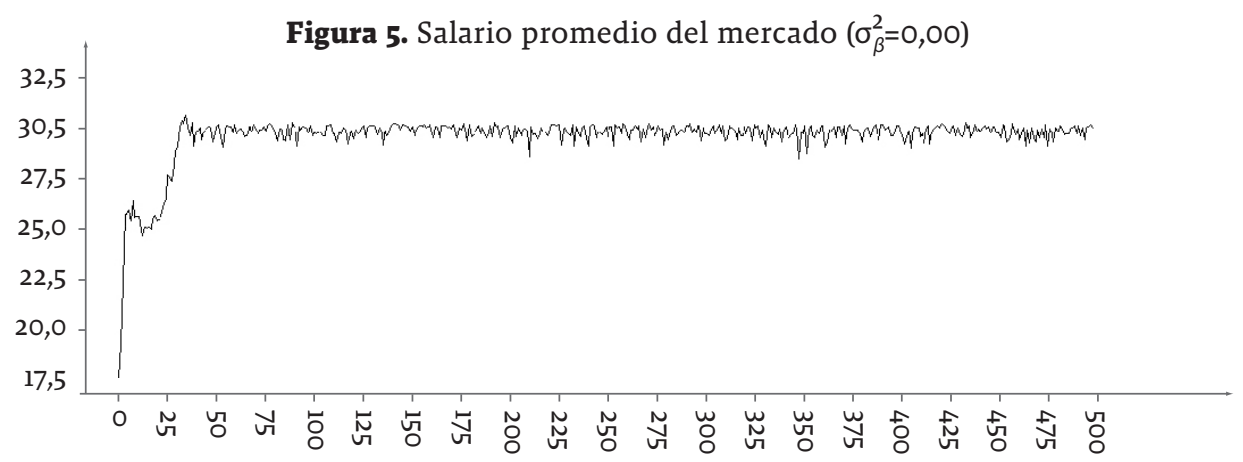

Fuente: elaboración propia.

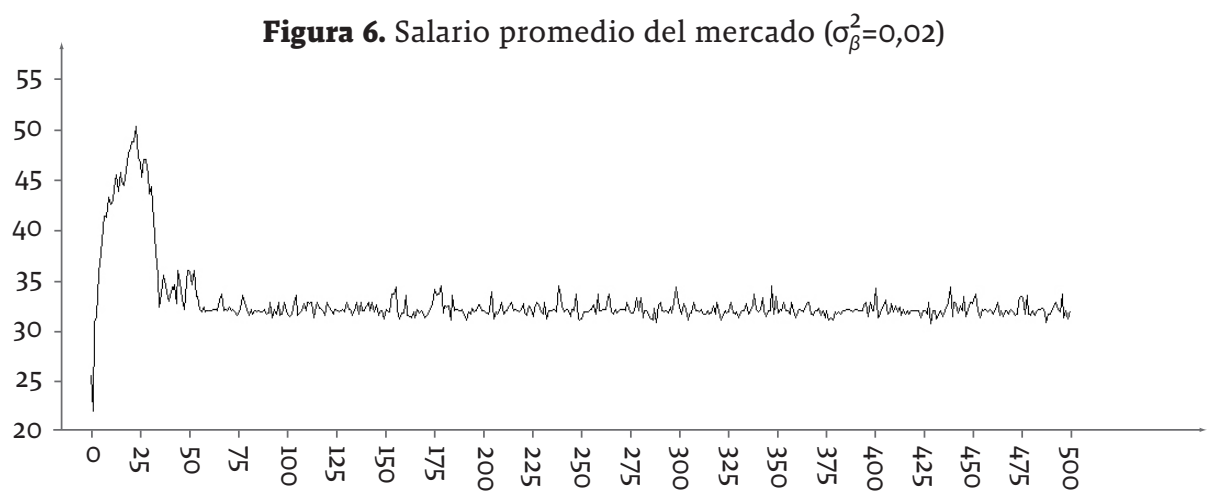

Fuente: elaboración propia.

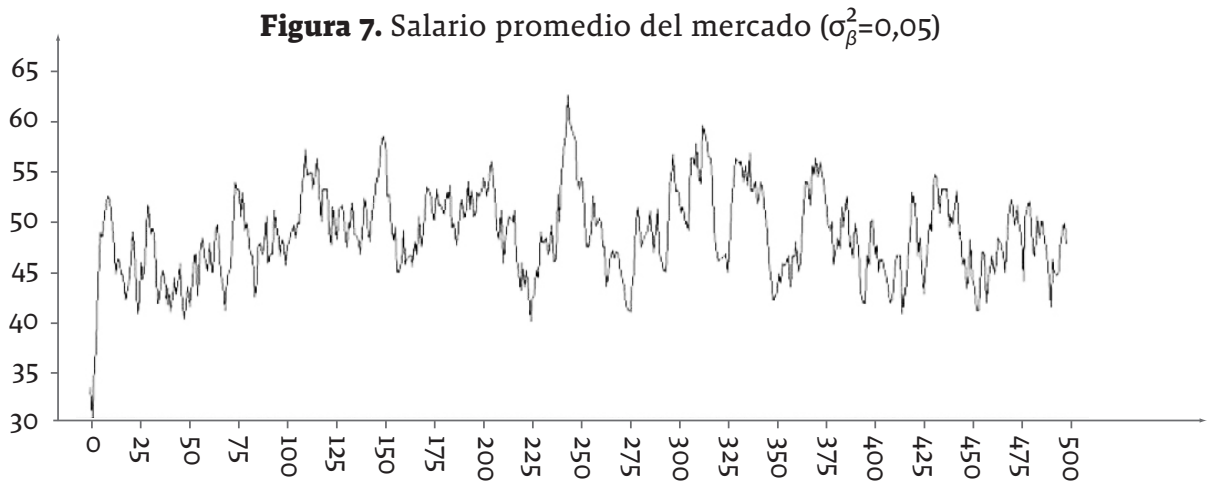

Fuente: elaboración propia.

\subsection{Escenario de simulación 3}

Este escenario simula un submercado del trabajo para firmas del sector menos productivo de la economía, intensivas en mano de obra no calificada. La heterogeneidad de la fuerza de trabajo se induce en este mercado artificial, asumiendo diferencias en la percepción de los individuos acerca del salario de referencia $w_{a}$. 
En efecto, si el salario de referencia se interpreta como un salario justo, o como el valor de la fuerza de trabajo de Marx, esta variable económica adquiere un carácter individual (heterogéneo), porque depende de las necesidades físicas (salud, alimentación, vivienda, calzado, etcétera), de capacitación, culturales, educativas y recreativas del trabajador y su familia, surgidas de las condiciones sociales, culturales e históricas que configuran el entorno general del trabajador.

Los trabajadores con un salario de referencia $w_{a}$ más bajo son más productivos, porque a partir de (10) y (11), $\frac{\partial e}{\partial w_{a}}<0$. Igual que en el escenario de simulación 2, las firmas que ofrecen salarios más altos contratan a los trabajadores que más se esfuerzan (céteris paribus), es decir, con un salario de referencia más bajo. Así, la función de producción de las firmas queda de la siguiente forma:

$$
y_{i}=A *\left[\sum_{i=1}^{L_{i}} e_{j}\left(w_{i}, w_{a j}\right)\right]^{a}
$$

Los salarios de referencia $w_{a j}$ para cada uno de los $\bar{L}$ individuos que componen la fuerza de trabajo son generados a partir de una distribución normal:

$$
w_{a j} \sim N\left(\bar{w}, \sigma_{w_{a}}^{2}\right)
$$

Donde $\bar{w}$ es el salario promedio del mercado.

Las figuras 8 a 12 exhiben los resultados de la simulación generados a partir de una variabilidad en el salario de referencia de $\sigma_{w_{a}}^{2}=2,0$. Se observa la existencia de dos sendas de salario: $w_{1}^{*} \cong 15, w_{2} \cong 22,5$ y de empleo $l_{1}^{*} \cong 60, l_{2}^{*} \cong 54$.

En el caso particular de homogeneidad de trabajadores, con salario de referencia igual al salario promedio del mercado, el análisis formal de esta cuarta parte encontró valores de: $w^{*}=20$ para el salario óptimo y de $l^{*}=58$ para el empleo óptimo. Entonces, la heterogeneidad en la percepción del salario de referencia genera salarios que pueden estar por encima $\left(w_{2}^{*} \cong 22,5\right)$ o por debajo $\left(w_{1}^{*} \cong 15\right)$ del salario óptimo $\left(w^{*}=20\right)$ para la situación de homogeneidad (figura 8).

Cuando se ofrece un salario más bajo $w_{1}^{*} \cong 15$, la oferta de empleo de las firmas es superior al óptimo bajo homogeneidad $l^{*}>58$ (figura 9), alcanzándose tasas de desempleo por debajo de $9 \%$ (figura 10 ). El salario más alto genera niveles de desempleo superiores cercanos a 20\% (figura 10).

La figura 11 revela que en la primera senda asociada a la oferta de salario más baja, el beneficio promedio de las firmas es muy inestable, va desde beneficios casi nulos, hasta valores superiores al nivel de 1.000. Es decir, los beneficios pueden estar por encima o por debajo del beneficio óptimo bajo homogeneidad $\left(\pi^{*} \cong 750\right)$. En la senda de oferta de salario más alta, los niveles de beneficios están más próximos a los de la situación de homogeneidad, pero tienen una ligera variabilidad. 


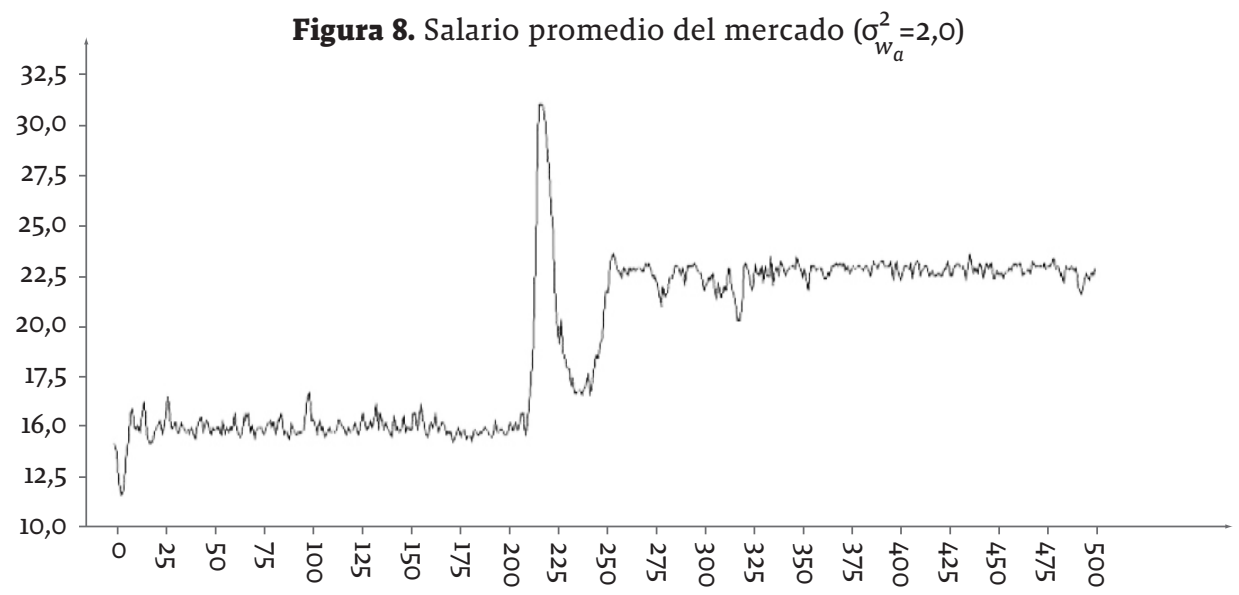

Fuente: elaboración propia.

Figura 9. Empleo promedio $\left(\sigma_{w_{a}}^{2}=2,0\right)$

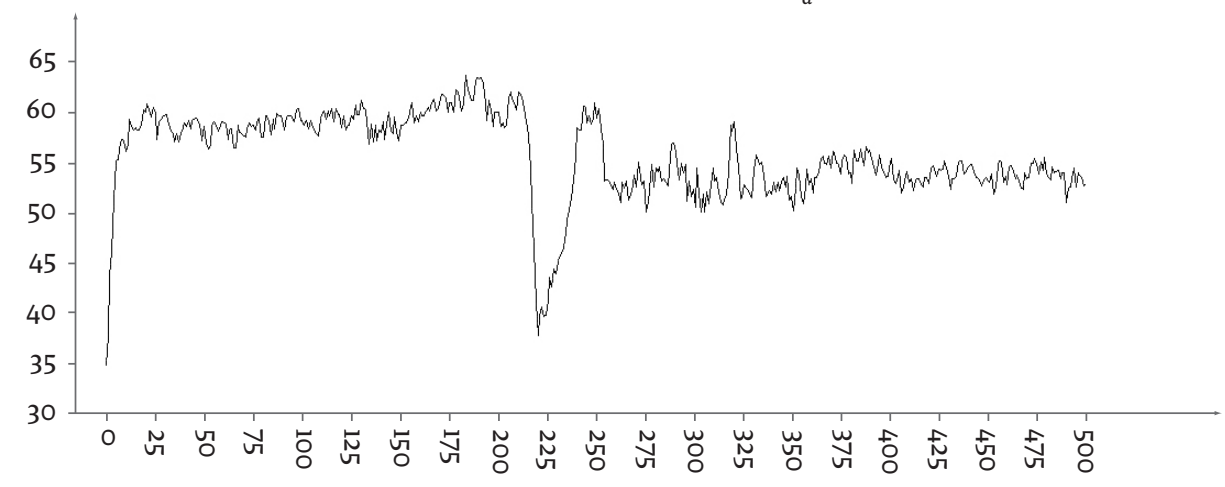

Fuente: elaboración propia.

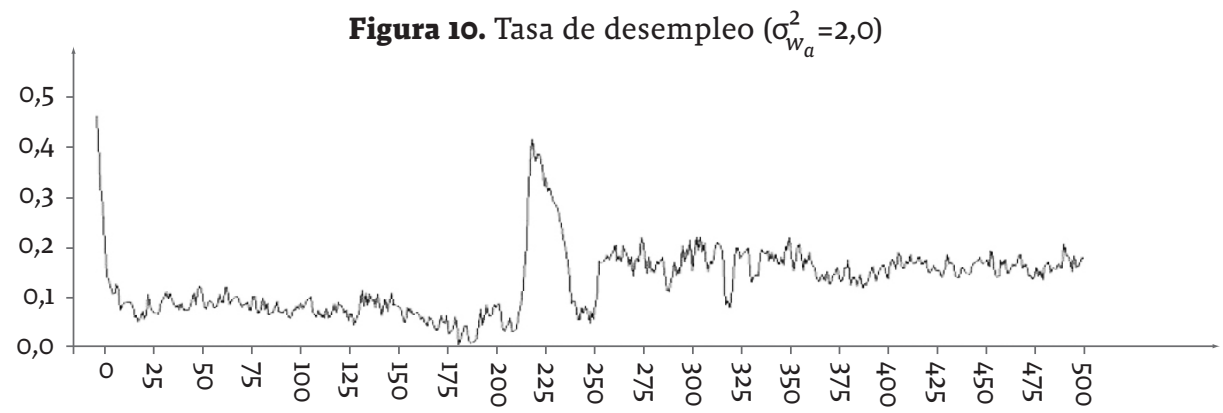

Fuente: elaboración propia. 
Figura 11. Promedio de beneficios $\left(\sigma_{w_{a}}^{2}=2,0\right)$

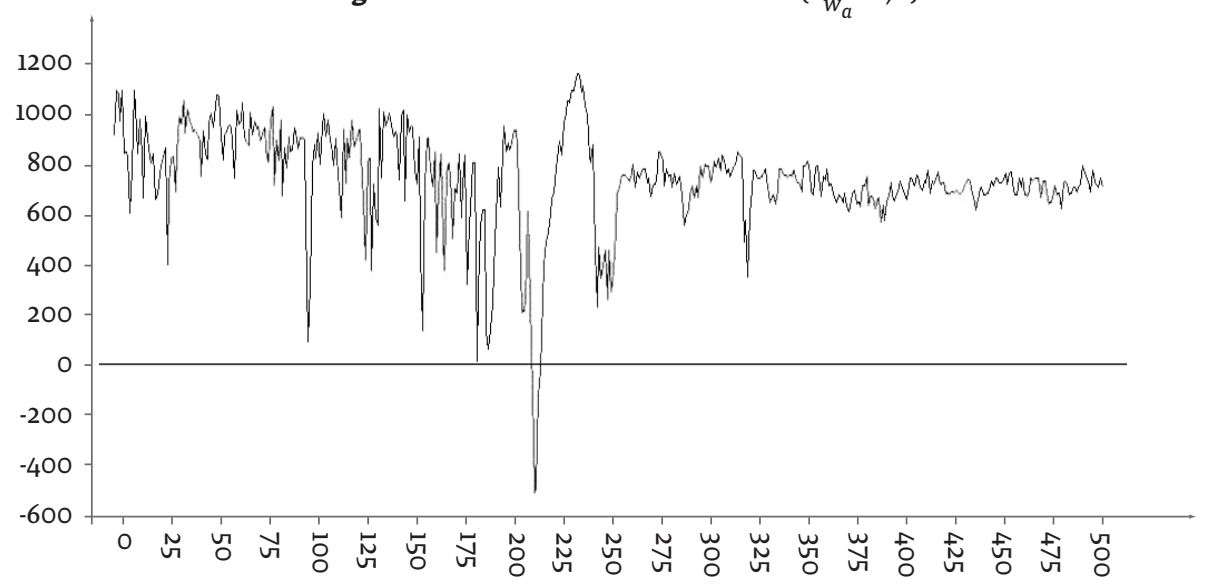

Fuente: elaboración propia.

Con la ayuda de las figuras 8, 9, 10 y 11 es posible explicar la dinámica de las variables de interés, especialmente el comportamiento que atañe a las dos sendas obtenidas como resultado la simulación. Así, se observa en las figura 8 y 9 que para la primera estrategia de salario de las firmas (la de salario bajo) la oferta de empleo de las firmas aumenta paulatinamente. El punto crítico se alcanza cuando las tasas de desempleo tienden a 0,0\% (figura 10), lo que implica, dada la heterogeneidad de los trabajadores, que con el paso de las generaciones los individuos que tienen salarios de referencia altos (por tanto, se esfuerzan menos) están cambiando su situación laboral de parados a empleados. Al contratar a los trabajadores menos productivos, los beneficios de las firmas caen, como se observa en la figura 11 (generación 210) y esto obliga a las firmas a cambios en las estrategias de salario y empleo. Es decir, las firmas ofrecen un salario más alto y reducen la oferta de empleo, que es lo observado en la senda dos.

Sin embargo, otro escenario posible es el siguiente: las firmas pueden optar por competir por los trabajadores que desempeñan un mayor nivel de esfuerzo (con el salario de referencia más bajo) ofreciendo salarios altos $\left(w^{*}=22,5\right)$. Sin embargo, dada la heterogeneidad de trabajadores, algunas firmas alcanzan resultados negativos en sus beneficios, al ofrecer salarios altos a trabajadores que se esfuerzan poco. Allí puede surgir nuevamente la estrategia de salario bajo $\left(w^{*}=15\right)$.

\subsubsection{Efecto del salario mínimo}

La figura 12 muestra el resultado de la simulación cuando existe un salario mínimo con magnitud de 15 unidades, así que $w \in$ [15,32]. En este escenario, como el salario promedio inicial es aproximadamente 23,5 - muy superior al valor de 15 - el salario promedio converge al salario alto $\left(w^{*}=22,5\right)$, porque el esfuerzo de los trabajadores de las empresas que ofrezcan salarios bajos $\left(w^{*}=15\right)$ sería demasiado bajo en comparación con el salario promedio que es el de referencia. Es decir, la existencia del salario mínimo obliga a las empresas a competir mediante salarios altos. 
Figura 12. Salario promedio del mercado $\left(\sigma_{\beta}^{2}=2,0\right)$ y salario mínimo

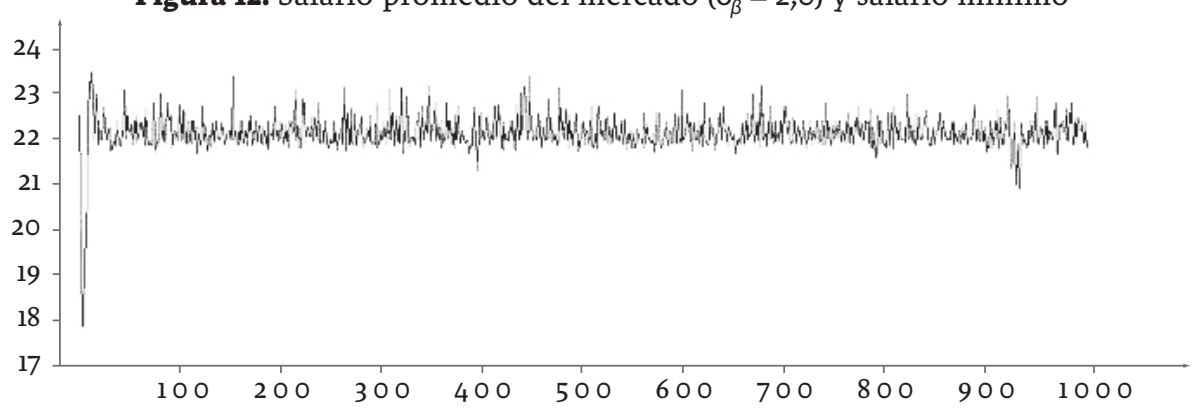

Fuente: elaboración propia.

\subsection{Escenario de simulación 4}

Este escenario simula un mercado del trabajo que combina las condiciones del escenario 2 zy del escenario 3. Es decir, existen dos clases de firmas que demandan trabajo, las empresas que son intensivas en mano de obra y las intensivas en capital y demandan mano de obra calificada. En este escenariơ se simulan tres casos:*el de homogeneidad de trabajadores, el de heterogeneidad en el parámetro de productividad, y el de heterogeneidad en el parámetro de productividad y en el salario de referencia que afecta el esfuerzo.

La tabla 2 registra los valores de los parámetros para la simulación. Las magnitudes de los parámetros de la función de producción son más altas para las firmas del sector 1 que las del sector 2, con el propósito de que sean más productivas y demanden la mano de obra más calificada. Los valores elegidos también tienen como propósito que la estrategia de salario y empleo óptimo sean números enteros que pertenezcan a los intervalos factibles para dichas estrategias.

Tabla 2. Valores de los parámetros

\begin{tabular}{|c|c|c|}
\hline \multicolumn{3}{|c|}{$\begin{array}{l}\text { Parámetros para la simulación } \\
\text { Función de producción }\end{array}$} \\
\hline \multirow[t]{2}{*}{ Firmas sector 1} & $A_{1}$ & $a_{1}$ \\
\hline & 250 & 0,80 \\
\hline \multirow[t]{2}{*}{ Firmas sector 2} & $A_{2}$ & $a_{2}$ \\
\hline & 179 & 0,62 \\
\hline \multirow{2}{*}{$\begin{array}{l}\text { Función de } \\
\text { esfuerzo }\end{array}$} & $\beta$ & $\boldsymbol{b}$ \\
\hline & 0,1875 & 2,0 \\
\hline \multicolumn{2}{|c|}{ Fuerza de trabajo: } & 2.560 \\
\hline \multicolumn{2}{|c|}{ Número de firmas sector 1} & 20 \\
\hline \multicolumn{2}{|c|}{ Número de firmas sector 2} & 20 \\
\hline \multicolumn{2}{|c|}{ Rango de estrategia de salario } & $w \in[1,64]$ \\
\hline \multicolumn{2}{|c|}{ Rango de estrategia de empleo } & $L \in[1,64]$ \\
\hline \multicolumn{2}{|c|}{ Probabilidad de mutación } & 0,05 \\
\hline
\end{tabular}

Fuente: elaboración propia 
Homogeneidad $\left(\sigma_{\beta}^{2}=0,0\right.$ y $\left.\sigma_{w_{f}}^{2}=0,0\right)$

Como era de esperarse, dada la productividad más alta de las firmas del sector 1 que las del sector 2 (valores de $A_{1}>A_{2} y \alpha_{1}>\alpha_{2}$ ), el sector 1 paga salarios más altos $\left(w_{1}^{\star} \cong 50\right)$ que el sector $2\left(w_{2}^{*} \cong 24\right)$ (figuras 13 y 14). Debido a la alta productividad del sector 1 , el ingreso marginal siempre es mayor que el costo marginal de contratar cada trabajador adicional (salario) para el rango factible de contratación $L \in[1,64]$. Por lo tanto, el empleo contratado por el sector 1 es $\left(L_{1}^{*} \cong 64\right)$.

Figura 13. Salario promedio del sector 1

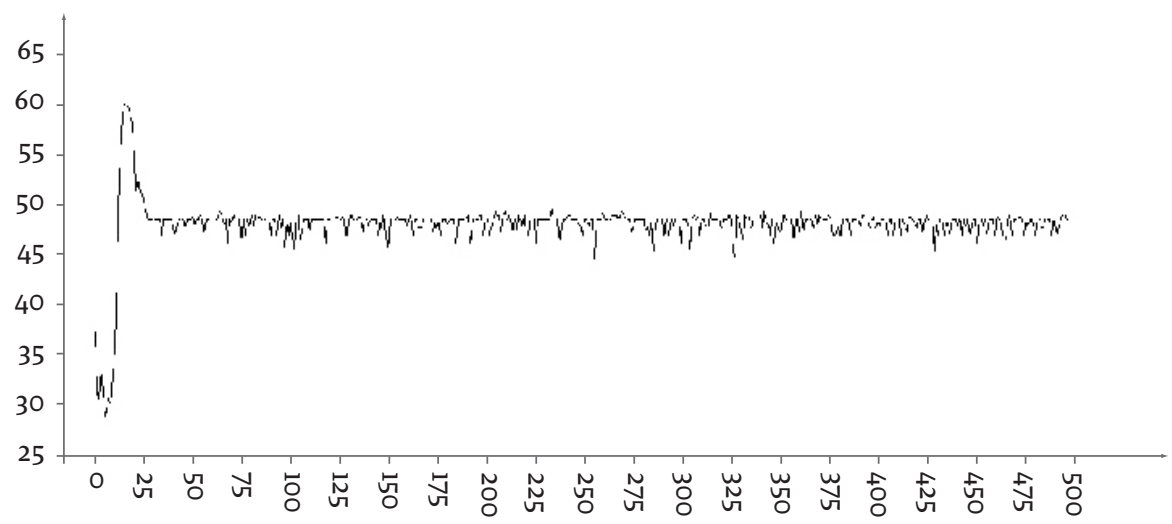

Fuente: elaboración propia.

En promedio las empresas del sector 2 tienen un nivel de contratación de empleo $L_{2}^{*} \cong 40$ (figura 15 ). El desempleo resultante es de aproximadamente $20 \%$, generado por la restricción de contratación del sector 1 y porque el sector 2 no tiene la capacidad de absorber esta mano de obra, dada su baja productividad. Básicamente, este caso sirve como escenario de comparación contra las situaciones de heterogeneidad.

Figura 14. Salario promedio del sector 2

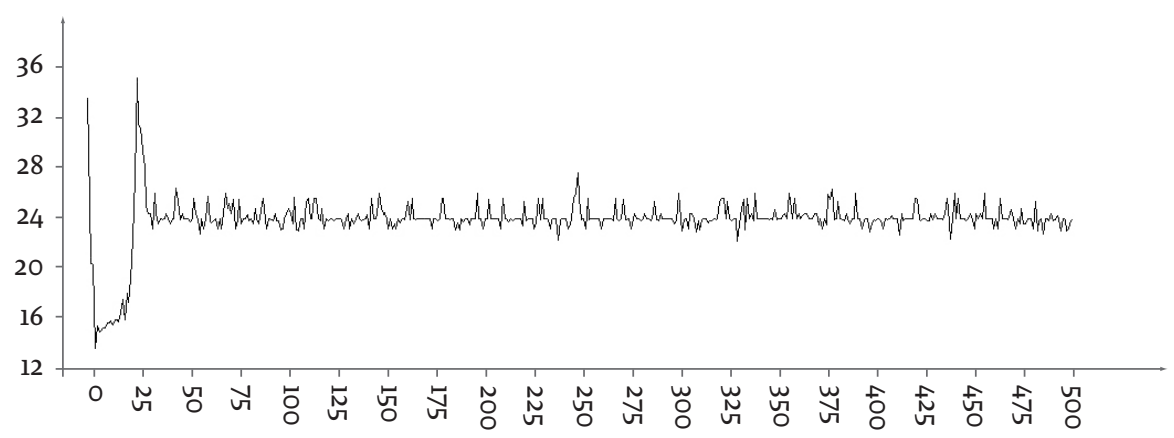

Fuente: elaboración propia. 
Figura 15. Empleo promedio del sector 2

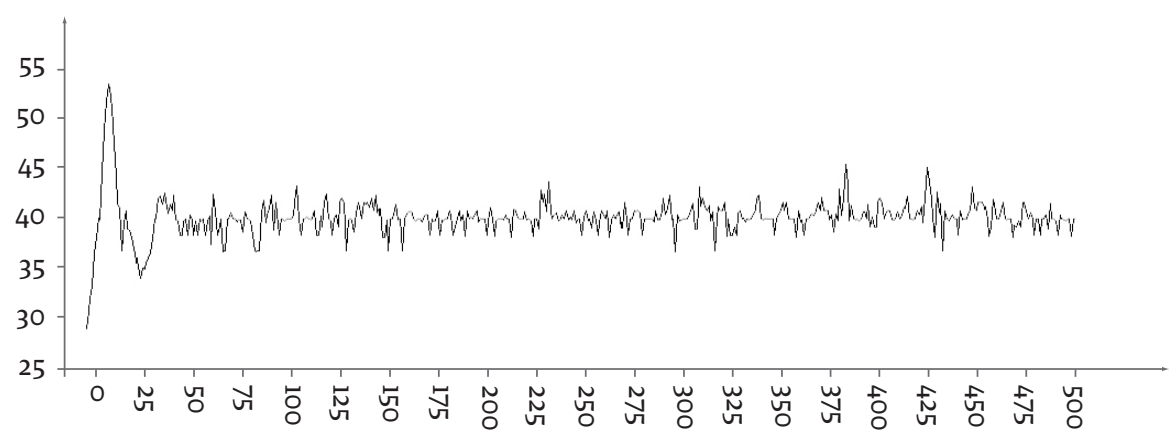

Fuente: elaboración propia.

\section{Heterogeneidad en el parámetro de productividad}

$\left(\sigma_{\beta}^{2}=0,6\right.$ y $\left.\sigma_{w_{a}}^{2}=0,0\right)$

Cuando se agrega variabilidad en la cualificación o habilidad de los trabajadores, la competencia por contratar a los mejores trabajadores en el sector 1 hace que el salario pagado por las firmas de ese sector alcance el máximo posible $w_{1}^{*} \cong 64$. El empleo contratado por las firmas de este sector es también el máximo posible $L_{1}^{*} \cong 64$. Debido al incremento en la oferta de salario del sector $1^{7}$, tiende a aumentar el salario promedio del mercado conformado por los sectores 1 y 2, lo que impacta el salario de referencia. El salario que paga el sector 2 aumenta $w_{2}^{*} \cong 26,5$ (figura 16) para contrarrestar la caída en el esfuerzo de los trabajadores producto del cambio en el salario de referencia.

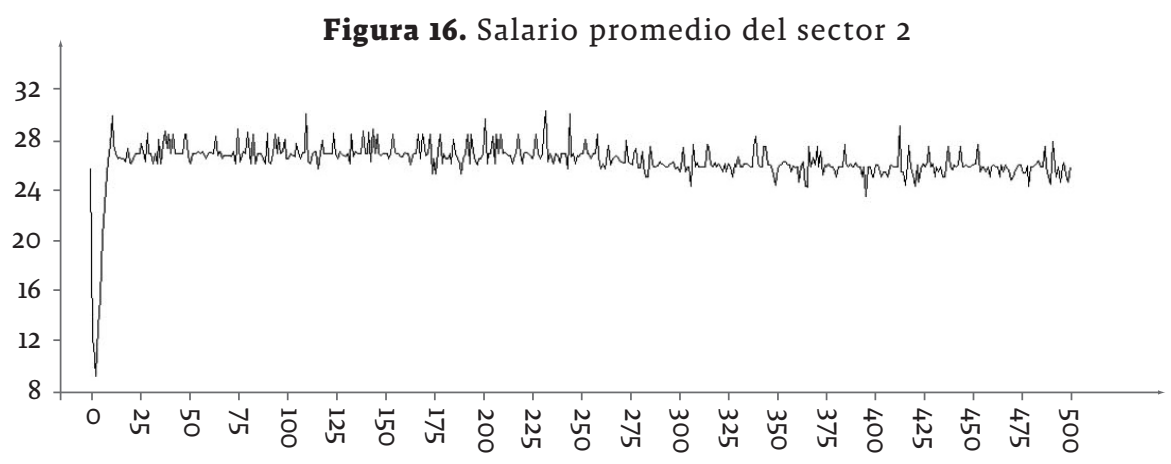

Fuente: elaboración propia.

El incremento en el salario promedio ofrecido por el sector 2 requiere que la productividad de las firmas sea más alta, por tanto, dado que la productividad marginal del trabajo es decreciente, se contratan menos trabajadores en el

7 Comparado con el de homogeneidad. 
sector 2 , así que la oferta de empleo cae a $L_{2}^{*} \cong 37$ (figura 17). El desempleo es de aproximadamente $23 \%$.

Figura 17. Empleo promedio del sector 2

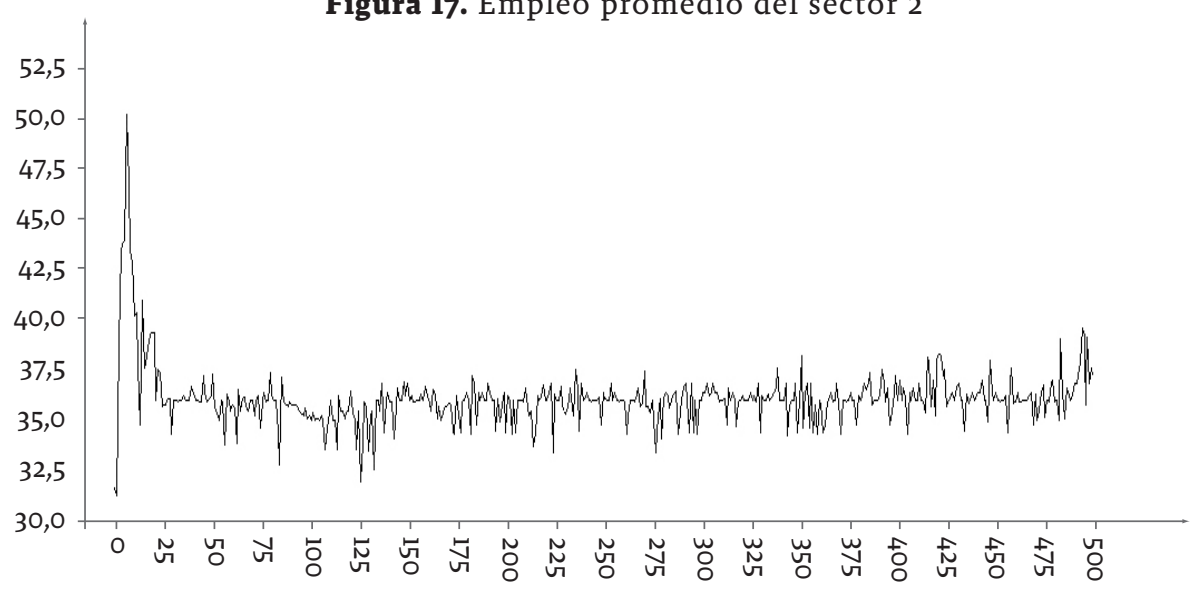

Fuente: elaboración propia.

Heterogeneidad en la productividad y esfuerzo $\left(\sigma_{\beta}^{2}=0,6\right.$ y $\left.\sigma_{w_{a}}^{2}=0,2\right)$

Cuando además de la variabilidad en la cualificación de los trabajadores, se agrega la variabilidad en la percepción de su salario de referencia, los salarios promedio ofrecidos por los sectores 1 y 2 son similares a los del caso anterior, $w_{1}^{*} \cong 64$ y $w_{2} \cong 27$ (figuras 18 y 19), así como las demandas de trabajo $L_{1}^{*} \cong 64$, y $L_{2}^{*} \cong 37$ (figuras 20 y 21); solo se observa una mayor variabilidad en demanda de trabajadores del sector 2 (figura 21).

El desempleo resultante es de aproximadamente $23 \%$. En este caso, los salarios de referencia del sector 2 no siguen una estrategia de salario bajo, porque el salario de referencia es una ponderación de los salarios de los sectores 1 y 2 , y con la estrategia de salario bajo, el esfuerzo de los trabajadores sería muy limitado.

Figura 18. Salario promedio del sector 1

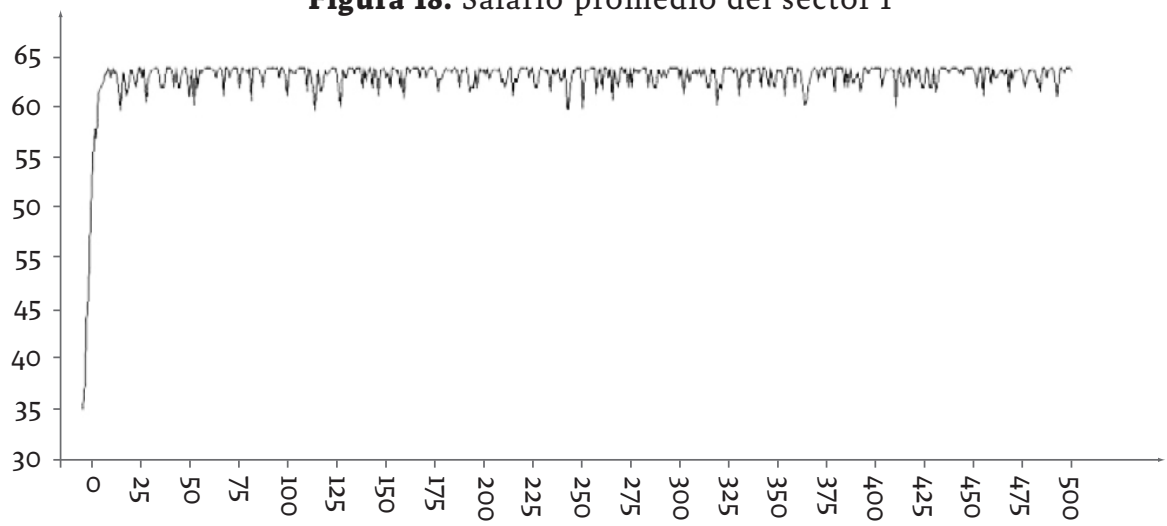

Fuente: elaboración propia. 
Figura 19. Salario promedio del sector 2

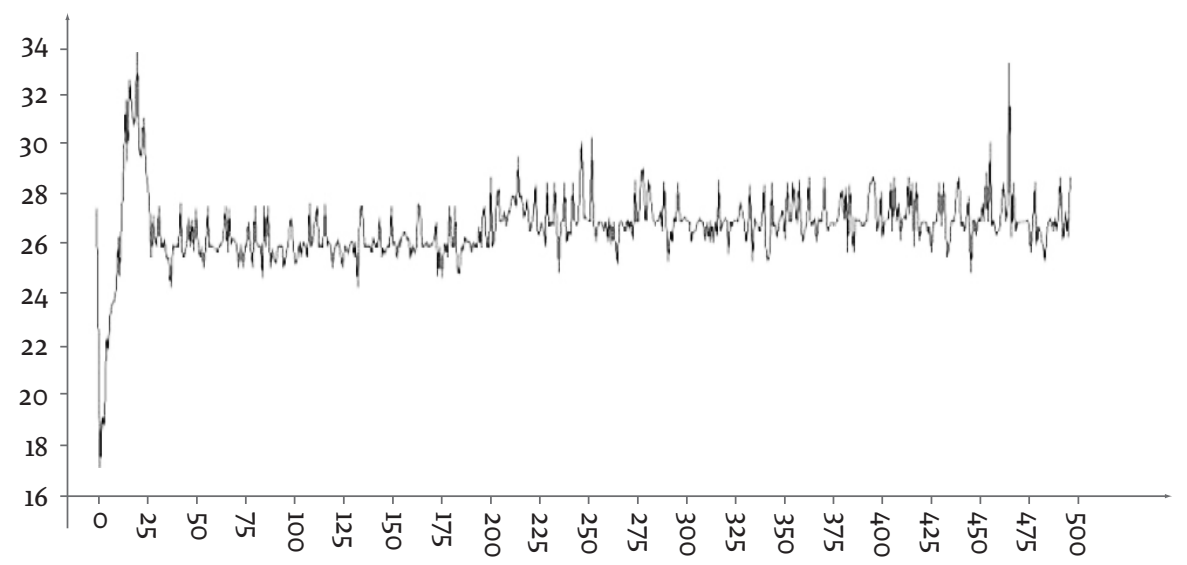

Fuente: elaboración propia.

Figura 20. Empleo promedio del sector 1

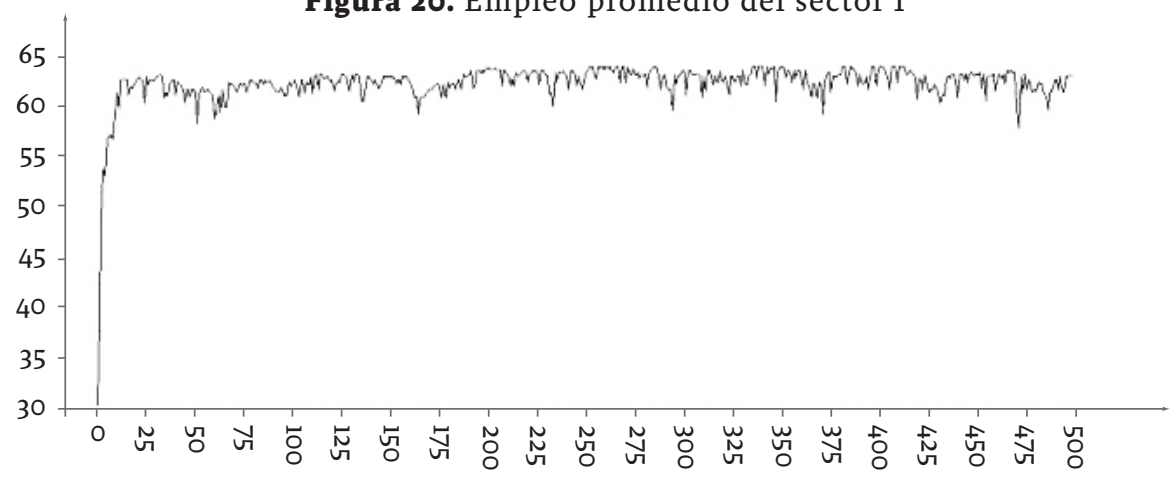

Fuente: elaboración propia.

Figura 21. Empleo promedio del sector 2

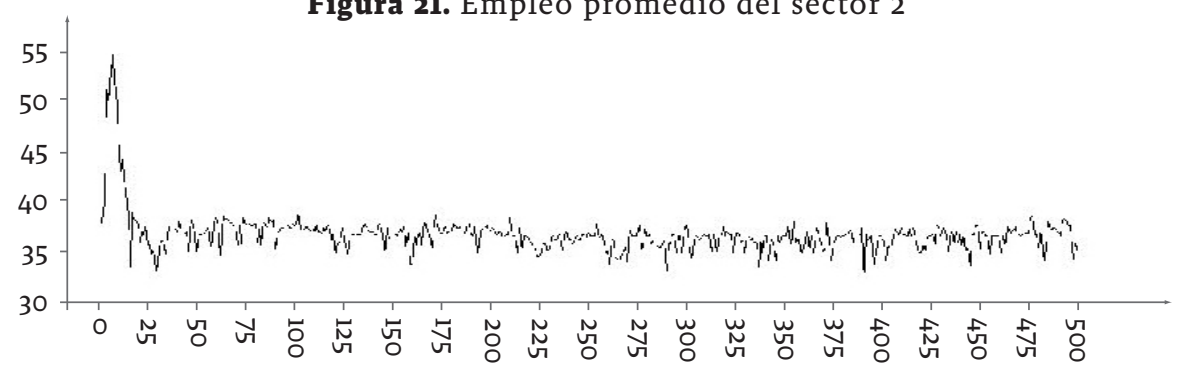

Fuente: elaboración propia. 


\section{Conclusiones}

En este artículo se utilizaron los algoritmos genéticos para modelar el comportamiento de firmas y trabajadores heterogéneos en un mercado de trabajo artificial. Dicha estrategia de simulación se sustenta en ciertas condiciones como la racionalidad limitada y el manejo de información asimétrica por parte de las firmas, que hacen de la modelación tradicional ortodoxa, una aproximación inadecuada para el tratamiento de este problema. Cuando las firmas no observan directamente el grado de incumplimiento del trabajador o su función de esfuerzo, es preferible la adopción del supuesto de racionalidad limitada, y permitir que sean las interrelaciones entre los agentes y el aprendizaje inductivo representado por el algoritmo genético quienes gobiernen la dinámica del mercado laboral artificial.

Las simulaciones recrean distintas condiciones del mercado del trabajo, bajo diferentes supuestos sobre el comportamiento de los agentes del mercado (firmas y trabajadores), y con condiciones distintas: homogeneidad de firmas y trabajadores, comparado contra escenarios diferentes como homogeneidad de firmas-heterogeneidad de trabajadores y heterogeneidad de firmas y trabajadores. La modelación permitió identificar la dinámica de los salarios y el empleo cuando se toman en cuenta dichas heterogeneidades y el supuesto de racionalidad limitada.

Como punto de partida, se demostró que es posible replicar los resultados del análisis formal mediante el algoritmo genético, en el escenario de línea base (homogeneidad de firmas y trabajadores). Esto aporta confianza en la validez del instrumento de simulación.

En el submercado de trabajo de las firmas del sector más productivo de la economía, las empresas pagan un salario lo suficientemente alto, como para aprovechar completamente las habilidades de sus empleados, lo que ocurre cuando su esfuerzo es igual a uno. Con la introducción de la heterogeneidad de los trabajadores, a medida que aumenta la variabilidad de las habilidades, el salario ofrecido por las firmas aumenta (con respecto a la línea base de homogeneidad), así como su varianza, dando origen a ciclos. Estos ciclos se explican por el aprendizaje inductivo, que implica estrategias de salarios cada vez más altos para competir por los trabajadores más calificados. Eventualmente algunas firmas resultan perdedoras, al pagar salarios altos por trabajadores no tan capacitados, y la tendencia al alza de los salarios de revierte, proceso que es gobernado por el aprendizaje inductivo. Sin embargo, los salarios nunca caen mucho, porque el salario debe satisfacer al trabajador de forma tal que se garantice su máximo esfuerzo.

En el submercado del trabajo del sector menos productivo de la economía, se encontraron dos sendas de salario opuestas, así que no existe un único equilibrio estable. El aprendizaje inductivo puede conducir a una estrategia de salario bajo (alto), y mayor (menor) demanda de trabajo (con respecto a la línea base de homogeneidad).

La estrategia de salario bajo es factible dado que la caída en el esfuerzo del trabajador, provocada por la disminución paulatina de salarios, es compensada por el efecto positivo sobre el esfuerzo, originado por las reducciones en la tasa 
de desempleo y el salario de referencia. Así que se concluye que en el mercado de trabajo de mano de obra menos calificada se podrían llegar a fijar salarios que estén por debajo del salario que equilibra el mercado.

También es posible que el aprendizaje inductivo gobierne una estrategia de salario alto, porque las firmas compiten por los trabajadores más calificados para maximizar sus beneficios. Sin embargo, dada la heterogeneidad de trabajadores, algunas firmas resultan perdedoras porque ofrecen salarios altos a trabajadores con bajo nivel de esfuerzo. Así puede surgir la estrategia de ofrecer salarios bajos, para evitar la existencia de estas firmas perdedoras.

Se puede concluir también, que la existencia del salario mínimo obliga a las empresas a competir por trabajadores calificados, mediante la oferta de salarios altos, porque la estrategia de salarios bajos no sería legal. En este caso, puede ser que el salario mínimo mejore la competitividad internacional, porque mejora la productividad.

Al simular un solo mercado de trabajo conjunto, cuando se introduce la variabilidad en la habilidad, la competencia por contratar a los mejores trabajadores en el sector 1 hace que el salario pagado por las firmas del sector aumente. El salario del sector 2 también aumenta, para compensar el aumento en el salario de referencia (salario promedio del mercado). Por eso la estrategia de salario bajo ya no es una alternativa. El desempleo es más alto, porque el incremento en el salario ofrecido por el sector 2 requiere que la productividad de las firmas sea más alta, por tanto, dado que la productividad marginal del trabajo es decreciente, se contratan menos trabajadores en el sector 2. Cuando se agregó la variabilidad en la percepción del salario de referencia de los trabajadores, los salarios promedio ofrecidos por los sectores 1 y 2 resultaron muy similares a los del caso anterior, pero se observó mayor variabilidad.

En general, se puede concluir que la heterogeneidad en la calificación de los trabajadores, o en su percepción del salario de referencia, obliga a las firmas a competir por los trabajadores más calificados, o que se esfuerzan más céteris paribus, ofreciendo salarios más altos, especialmente cuando la economía está sujeta al régimen de salario mínimo, o la percepción del salario de referencia es un promedio del mercado conjunto del trabajo. Este hecho impacta negativamente los beneficios de las firmas, beneficia a los trabajadores contratados, pero genera mayor desempleo.

Se deduce, por tanto, que políticas de entrenamiento laboral o de homogeneización de la percepción del salario justo, como por ejemplo la política de publicación de una cifra de salario digno en Ecuador, puede tener efectos directos y positivos sobre el empleo.

\section{Referencias bibliográficas}

Bosworth, Derek, Peter Dawkins y Thorsten Stromback. The Economics of the Labour Market. Harlow: Addison Wesley, 1996.

Caraballo, Pou. «Salarios, productividad y empleo: la hipótesis de los salarios de eficiencia». Revista Cuadernos de Estudios Empresariales, nº 6, 1996: 106-127.

Durán, Julián. «¿Determinantes del salario de reserva en el mercado laboral de Cali en el 2004?». Documentos de Trabajo del CIDSE, nº 85, 2005: 1-21. 
Faria, Luis. «Agent-based Model in Labor Market as a Third Way to Micro/macro Relation: A New Paradigm». Ponencia presentada en wild@ace 2004 Conference, Industry and Labor Dynamics, organizada por LABORatorio R. Revelli Centre for Employment Studies. Turín, Italia, diciembre 3-4 de 2004.

Geisendorf, Silvye. "Genetic Algorithms in Resource Economics Model». Santa Fe Institute, Working Paper, nº 99-08-058, 1999: 1-26.

Holland, John. Adaptation in Natural and Artificial Systems. Ann Arbor: University of Michigan Press, 1975.

Kosciuczyk, Vera. «El aporte de la economía conductual o Behavioural Economics a las políticas públicas: una aproximación al caso del consumidor real». Palermo Business Review, $\mathrm{n}^{\circ}$ 7, 2012: 23-40.

Méndez, Jhon. «Adaptación de algoritmos genéticos en la simulación del comportamiento estratégico de los agentes contaminadores ante el cobro de tasas retributivas». Cuadernos de Administración, Vol. XXI, n 35, 2008: 165-187.

Monte, Paulo, Hilton Ramalho y Márcia Pereira. "O salário de reserva e a oferta de trabalho: evidências para o Brasil». Brazilian Journal of Applied Economics, Vol. 15, n 4, 2011: 613-639.

Prasad, Eswar. «What Determines the Reservation Wages of Unemployed Workers? New Evidence from German Micro Data». IZA Discussion Papers n 694 (enero 2003): 32-52.

Riechmann, Thomas. «Learning and Behavioral Stability. An Economic Interpretation of Genetic Algorithms». Journal of Evolutionary Economics, Vol. 9, $\mathrm{n}^{\circ} 2$, 1998: 225-242.

Riveros, Luis. «El enfoque de salarios de eficiencia y el ajuste económico en países en desarrollo». Desarrollo y Sociedad, n² 27, 1993: 25-46.

Schunk, Daniel. «Modeling the Use of Nonrenewable Resources Using a Genetic Algorithm». Sonderforschungsbereich Working Paper (Universität Mannheim), $n^{\circ}$ 03-23, 2003: 1-14.

Simon, Herbert. «A Behavioral Model of Rational Choice». The Quarterly Journal Economics, Vol. 69, $\mathrm{n}^{\circ}$ 1, 1955: 99-118.

Solow, Robert. «Another Possible Source of Wage Stickiness». Journal of Macroeconomics, Vol. 1, $\mathrm{n}^{\circ}$ 1, 1979: 79-82.

Summers, Lawrence. "Relative Wages, Efficiency Wages, and Keynesian Unemployment». American Economic Review, Vol. 78, n² 2, 1988: 383-388.

Wadhwani, Suchil, y Martin Wall. «A Direct Test of the Efficiency Wage Model Using UK Micro-Data». Oxford Economic Papers, Vol. 43, n 4, 1991: 529-548.

Weiss, Andrew. "Job Queues and Layoffs in Labor Markets with Flexible Wages». Journal of Political Economy, ${ }^{\circ}$ 58, 1980: 526-538.

Weiss, Andrew, y Ruqu Wang. «A Sorting Model of Labor Contracts: Implications for Layoffs and Wage-Tenure Profiles». NBER Working Paper, $\mathrm{n}^{\circ}$ 3.448, 1990: 1-53.

Winoto, Pinata. "Genetic Algorithm and Social Simulation». Proceedings of the 7th Pacific Rim International Conference on Artificial Intelligence, Vol. 2.417, 2002: 148-157.

Yellen, Janeth. "Efficiency Wage Models of Unemployment». American Economic Review Papers and Proceedings, $\mathrm{n}^{\circ} 74,1984$ : 200-205. 